This article was downloaded by: [National Taiwan University]

On: 20 November 2009

Access details: Access Details: [subscription number 908165927]

Publisher Taylor \& Francis

Informa Ltd Registered in England and Wales Registered Number: 1072954 Registered office: Mortimer House, 3741 Mortimer Street, London W1T 3JH, UK

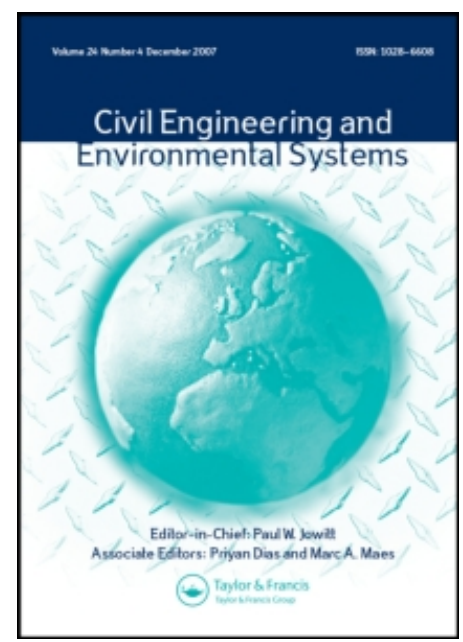

\title{
Civil Engineering and Environmental Systems
}

Publication details, including instructions for authors and subscription information:

http://www.informaworld.com/smpp/title content=t713455031

\section{OPTIMAL BALANCE BETWEEN LAND DEVELOPMENT AND GROUNDWATER CONSERVATION IN AN UNCERTAIN COASTAL ENVIRONMENT}

Shin-Cheng Yeh ${ }^{\mathrm{a}}$; Ching-Pin Tung ${ }^{\mathrm{b}}$

a Graduate Institute of Environmental Education, National Kaohsiung Normal University, Kaohsiung,

Taiwan 824, Republic of China. ${ }^{b}$ Department of Agricultural Engineering, National Taiwan University,

Taipei, Taiwan 116, Republic of China.

To cite this Article Yeh, Shin-Cheng and Tung, Ching-Pin'OPTIMAL BALANCE BETWEEN LAND DEVELOPMENT AND GROUNDWATER CONSERVATION IN AN UNCERTAIN COASTAL ENVIRONMENT', Civil Engineering and Environmental Systems, 20: 2, 61-81

To link to this Article: DOI: $10.1080 / 10286600290010258$

URL: http://dx.doi.org/10.1080/10286600290010258

\section{PLEASE SCROLL DOWN FOR ARTICLE}

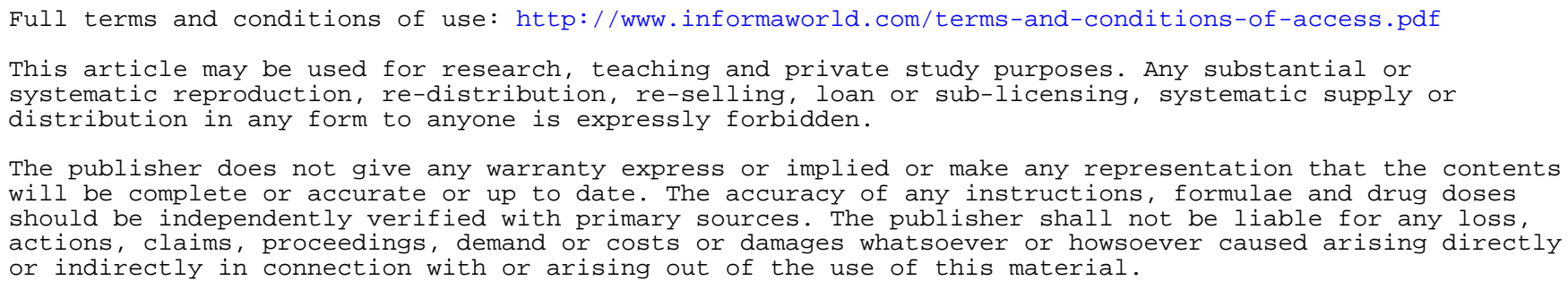




\title{
OPTIMAL BALANCE BETWEEN LAND DEVELOPMENT AND GROUNDWATER CONSERVATION IN AN UNCERTAIN COASTAL ENVIRONMENT
}

\author{
SHIN-CHENG YEH $^{\mathrm{a}, *}$ and CHING-PIN TUNG ${ }^{\mathrm{b}}$ \\ ${ }^{a}$ Graduate Institute of Environmental Education, National Kaohsiung Normal University, Kaohsiung, \\ Taiwan 824, Republic of China; ${ }^{\mathrm{b}}$ Department of Agricultural Engineering, National Taiwan \\ University, Taipei, Taiwan 116, Republic of China
}

(Received 9 June 2001; In final form 15 November 2001)

\begin{abstract}
An optimization problem for balancing land carrying capacity and groundwater consumption in Central Taiwan was solved using a problem-oriented grey linear programming (POGLP) algorithm. Satisfactory grey solutions were obtained through formulating and solving the proposed POGLP models. These models provide useful information to decision makers regarding the possible ranges of final alternatives when system parameters are highly uncertain. Results indicate that all transferable lands currently used for agriculture and fish cultivation should be converted into other usage. This would conserve the groundwater resources, thereby preventing further land subsidence in that area. Grey sensitivity analyses performed well in the decision-making process when a set of interval regions instead of trend curves were systematically generated without increasing the complexity of the mathematical models.
\end{abstract}

Keywords: Problem-oriented grey linear programming; Groundwater conservation; Land subsidence; Optimization; Water resources planning; Land use

\section{INTRODUCTION}

Groundwater conservation is a critical issue in many countries where water deficiency problems are apparent. But land use planning is always correlated with groundwater conservation since land use development schemes demand consumption of water quantity and alter the quality. In both Central and Southern Taiwan, fish cultivation is a major production activity in most coastal regions. Groundwater is commonly used since surface water supplies are insufficient to meet the demands of fish cultivation. Consequently, local areas have been suffering from land subsidence due to long-term changes in groundwater. Development plans integrating land and water resources, which address issues of economic development and land subsidence prevention, are necessary.

\footnotetext{
* Corresponding author. E-mail: scyeh@nknucc.nknu.edu.tw
} 
The optimal balance between land use programs and water resource redistribution has been studied by many researchers in recent years. Sneh [1] considered water resource management used for the agriculture of Israel. Cooperation between farmers, industries, and researchers was promoted to achieve high efficiency of water use. Bevers and Troendle [2] developed a spatial optimization model to limit the cumulative effects caused by storm-flows in forest areas in the US. Chang et al. [3] used multiobjective programming techniques to find optimal management strategies for environmental and land resources in the Tweng-Wen Reservoir watershed. Many studies have also been done concerning land subsidence and groundwater management. Sato and Hoang [4] optimized groundwater pumping-rate to avoid land subsidence. Cleveland and Chuang [5] reported optimal aquifer management for controlling land subsidence while pursuing multiple goals of preserving the water supply, subsidence control, and energy development. However, the search for an integrated optimal management strategy to balance land uses and groundwater resource consumption subject to land subsidence prevention is still absent in the literature.

Uncertainties embedded in this systems analysis are critical since both parameter values and the decision-making process are not apparent. Traditionally, these uncertainties have been dealt with using probability theory and fuzzy mathematics [6]. However, these traditional approaches may not be suitable for dealing with uncertainties when different patterns are mixed in related problems. Grey programming is an optimization framework where uncertainties in system parameters are presented as grey numbers or intervals [7] that can transmit a variety of uncertain information relative to system parameters into the resulting planning scheme. Therefore, it is a potentially useful technique for identifying optimum allocations for land and water resources to achieve the sustainability goals.

In this study, grey linear programming (GLP) algorithms were applied to solving the optimization problem regarding land use patterns and groundwater resource planning for four coastal towns in Yun-Lin County, Central Taiwan. Grey solutions were obtained by solving a modified GLP model. The modified GLP model was proposed in such a way that it allows more applicable grey solutions to appear in the solution procedure. Results indicate that this problem-oriented GLP algorithm is applicable for achieving a set of desirable grey solutions. These solutions can offer decision makers sufficient information concerning possible ranges of management policy while taking into account the uncertainties embedded in the system.

\section{GREY LINEAR PROGRAMMING ALGORITHMS}

\section{Background}

Grey Programming (GP) is an optimization framework incorporating concepts of grey system theory $[8,9]$. Grey system theory is an alternative uncertainty modeling approach to those using probability theory and fuzzy set theory. Uncertain parameters in a system are presented as "grey numbers", i.e., intervals with known lower and upper bounds. In contrast uncertain elements are modeled as random variables with probability distributions in probability theory and fuzzy numbers with membership information in fuzzy set theory.

A major advantage of grey programming is that variations in system performance and decision variable values can be understood by solving relatively simple optimization models.

Traditionally, sensitivity analysis techniques were used to derive changes in system performance with respect to system parameters. A number of analyses are therefore needed in as much as many analyses are required for each parameter. By using grey programming, similar information can be obtained faster and simpler [7]. 
The pioneering work in developing GP algorithms was done by Huang et al. [7, 10-13] who proposed grey linear programming (GLP), grey integer programming (GIP), grey quadratic programming (GQP), and grey dynamic programming (GDP) models. These are further modified by incorporating fuzzy set theory [14] and were applied to municipal waste management problems in Canada. Applications of these GP algorithms and their modified versions were then presented. Chang et al. derived grey fuzzy multiobjective programming models for optimal planning of a reservoir watershed in Southern Taiwan $[15,16]$. Chang and Wang also applied GP in nonlinear forms in coastal wastewater treatment and ocean disposal systems [17]. Combinatory applications of grey programming and other system analysis tools have been also developed in recent years. Chang and Yeh analyzed the important property - "stability" in a set of grey compromise programming models for a watershed management case study [18]. Chang and Tseng also applied similar algorithms to an optimal evaluation of expansion alternatives for an existing air quality monitoring network in an urban area in Taiwan [19]. More recently, a grey input-output analysis methodology was developed and used for environmental cost allocation [20]. In the area of water resources management, Yeh proposed GLP, GQP, and GDP models for reservoir management problems [21]. Traditional GLP models were modified to avoid potential mathematical and operational problems.

\section{Traditional and Modified Grey Linear Programming Models}

A grey linear programming (GLP) model can be summarized using the following generalized form [7]:

$$
\begin{array}{ll}
\operatorname{Max} & f^{ \pm}=\mathbf{C}^{ \pm} \mathbf{X}^{ \pm} \\
\text {s.t. } & \mathbf{A}^{ \pm} \mathbf{X}^{ \pm} \leq \mathbf{B}^{ \pm} \\
& \mathbf{X}^{ \pm} \geq 0
\end{array}
$$

where $\mathbf{C}^{ \pm}=\left\{c_{j}^{ \pm}, j=1,2, \ldots, n\right\}, \mathbf{X}^{ \pm}=\left\{x_{j}^{ \pm}, j=1,2, \ldots, n\right\}, \mathbf{A}^{ \pm}=\left\{a_{i j}^{ \pm}, i=1,2, \ldots, m\right.$; $j=1,2, \ldots, n\}, \mathbf{B}^{ \pm}=\left\{b_{i}^{ \pm}, i=1,2, \ldots, m\right\}$.

Traditionally, grey solutions can be obtained through solving two submodels formulated on a set of rules developed by Huang et al. [7, 10-14]. Since difficulties may arise when any coefficient of a decision variable in the objective function, i.e., $c_{j}^{ \pm}$, is zero and the possibility of generating impractical solutions exist, these traditional GLP algorithms were modified [21]. Details of these formulations can be found in the literature and thus are not explained herein. The basic definitions relating to grey programming as used in model formulation are introduced in the appendix.

\section{Problem-Oriented Grey Linear Programming Models}

Grey Programming algorithms are intended to find some sets of grey solutions in the solution space. There can exist many stable sets of grey solutions and therefore different ones can result from using different GP models and assumptions in the processes of greylization. Although modified GLP models can apply to general LP models, further modifications can be made in order to obtain more practical grey solutions, as seen in problem-oriented GLP models. The principle for modification is simple: there must be stability within grey solutions. In other words the system performance and decision variable solutions must form stable sets of grey solutions, i.e., the system performance must be within its grey interval 
if all decision variables are within their corresponding grey intervals which result from the modified GLP submodels.

In optimization problem for resource allocation, as in the case of the land use and water resource planning for this research, the total amount of a specified resource may be constant. The traditional or modified GLP algorithms introduced in the preceeding may lead to mathematically sound grey solutions that are actually fixed numbers. Under such circumstances, these GLP formulations need to be revised so that interval instead of fixed solutions can be obtained. These problem-oriented revisions should be made based on a thorough understanding of the real system and the optimization problem to be solved. Generally speaking, the relationships between the decision variables and the system parameters, especially the RHS coefficients, need to be examined carefully to ensure that resulting solutions are applicable to the real-world systems. Figure 1 is the flowchart of the procedure for formulation and modification of POGL problems.

In this research, the modified GLP models discussed in preceeding sections, were used to derive grey solutions because some $c_{j}$ 's are zero in the objective function. Based on the

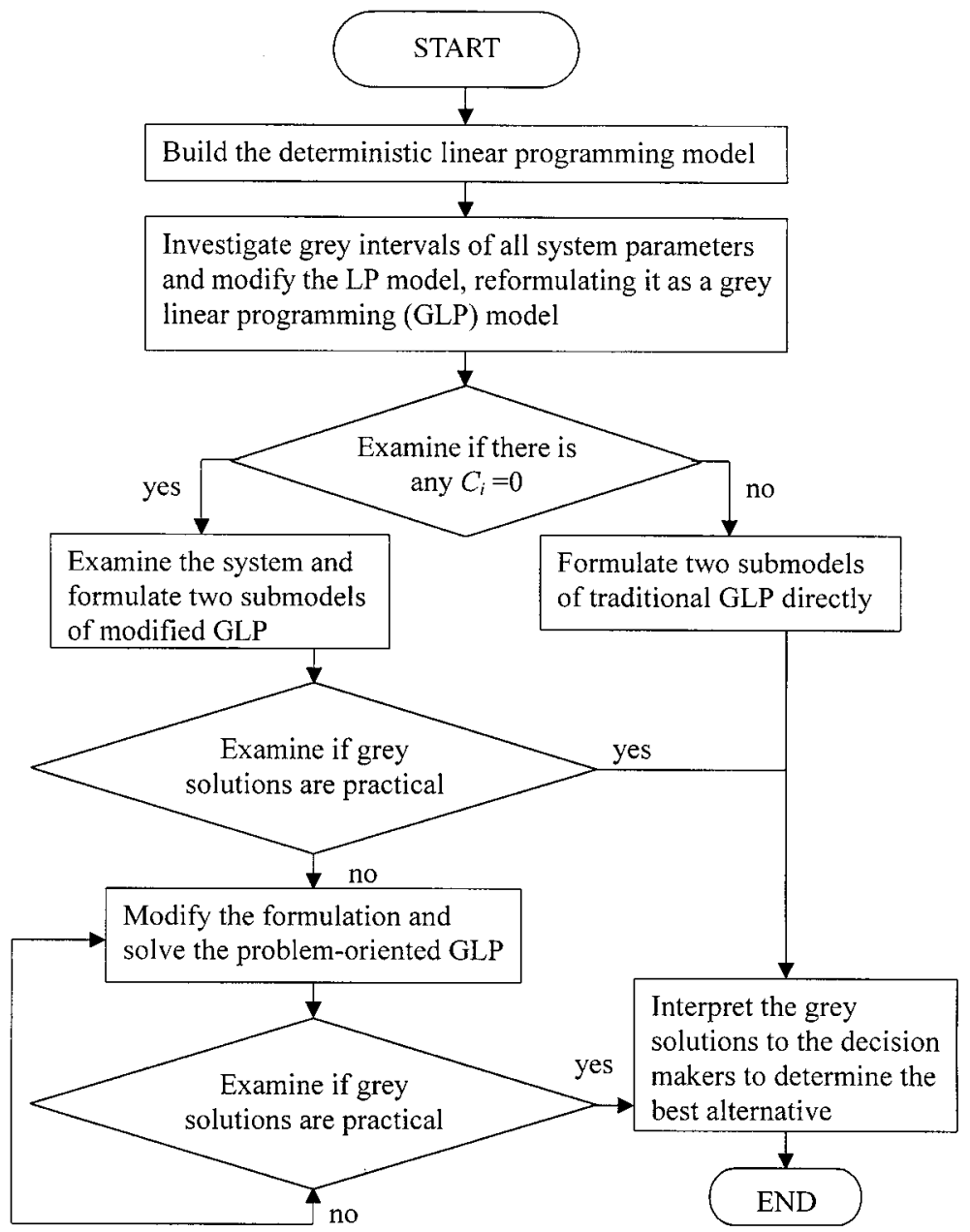

FIGURE 1 The flowchart for decision making using problem-oriented GLP. 
specific characteristics of the optimization problem of land use and water resource planning, the GLP models are further modified so that more reasonable grey solutions can be obtained.

\section{CASE STUDY}

\section{Site Description}

Taiwan is an island in the rim of the west Pacific Ocean, approximately two hundred kilometers from the southeast coastal area of Mainland China. Although there is abundant rainfall in this island, uneven distributions over temporal and spatial scales and high population density make the water resource management important. The annual amount of useable fresh surface water per capita is only 856 cubic meters. Based on the criteria set up by the International Population Action Organization, Taiwan is categorized with countries lacking water. Under these circumstances, further utilization of groundwater to support socio-economic activities is inevitable.

In Taiwan, the pumping of groundwater is normally carried out in a very short period of time in the coastal regions such that land subsidence has continuously occurred. From the 1940's to the 1980's, the most serious land subsidence problem occurred in the Taipei Metropolitan Area. Fortunately, the land stopped subsiding after the governmental intervention in the late 1980's. Meanwhile, the Central and Southern areas along the west coast became the emergency areas of land subsidence. For instance, one of the astonishing records of cumulative land subsidence is up to 2.88 meters in Chiatung Town, Pingtung County. The study area in this paper covers four towns - Mailao, Taishi, Shihu, and Kohu in Yun-Lin County (see Fig. 2). Between 1985 and 1994, approximately $300 \mathrm{~km}^{2}$ of land had subsided because of the overuse of groundwater in agriculture and fish cultivation. The maximum subsidence was 1.78 meters in Taishi Town.

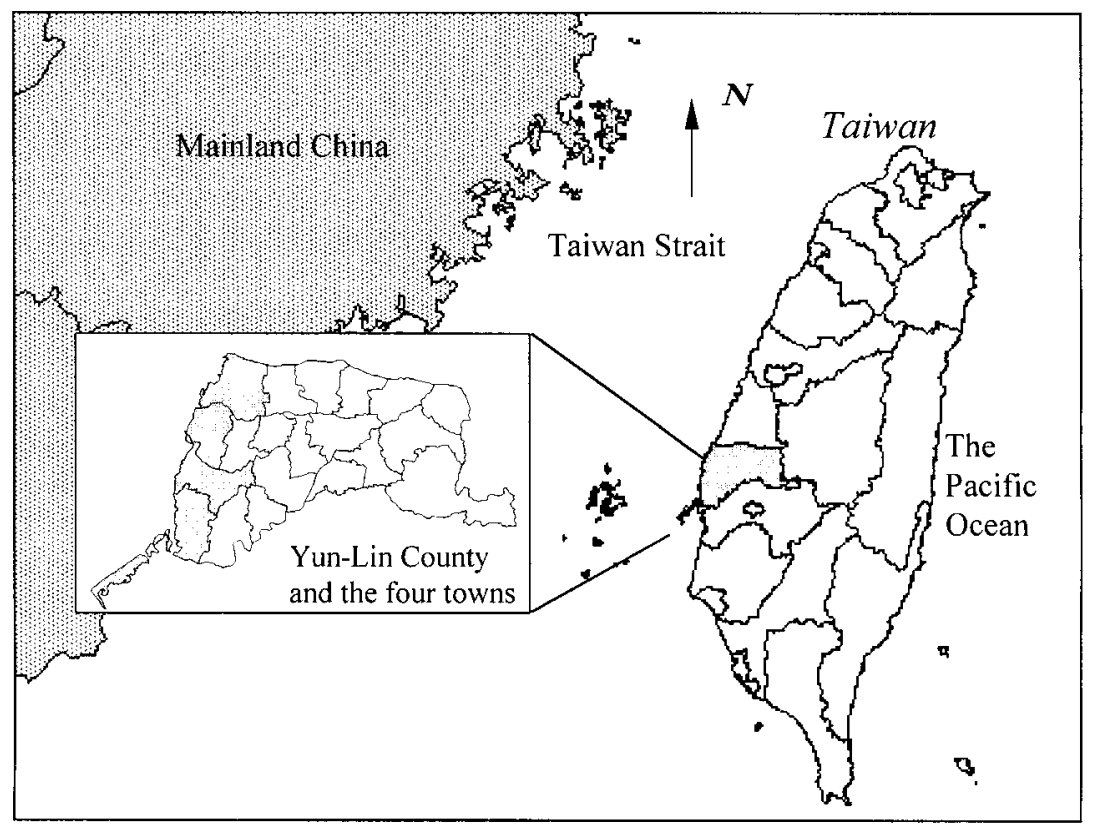

FIGURE 2 The geographical location of Taiwan, Yun-Lin County, and the four coastal towns. 
The reasons for abuse of the groundwater resources that has resulted in severe land subsidence are complex. The production potential is lower in the coastal areas because agricultural land has been salinized due to seawater intrusion. On the other hand, sufficient fresh surface water is not available to support large scale agricultural activities. Fish cultivation has consequently become one of the major economic activities. Groundwater is used to support fish cultivation and other industries because of its lower cost (e.g. it is free currently) and relative stability in both quantity and quality. A government agency intends to implement management plans for fish cultivation, including land use program and groundwater resource distribution.

\section{Identification of the Problem}

The Agriculture Council and the Ministry of Economic Affairs of the R.O.C. are now taking action to implement management plans to first decelerate and then stop land subsidence in this area. One of the major strategies is to control effectively the groundwater resources and land use planning as well as to promote the availability of surface water supply.

The goal of this study is to identify the land use management strategy in support of the optimal balance between land use and groundwater conservation. Land can be used for many purposes, including industry, commerce, agriculture, fish cultivation, residence, recreation and resources conservation. In general, different planning projects are being considered and the upper and lower limits for each type of land use are being specified in normal policy decision-making. To rectify the current condition of land subsidence, some land currently used for agriculture and fish cultivation must be switched to other uses.

The objective of this optimization analysis is to maximize the total benefit resulting from land uses minus consumption costs from various water uses. Control over groundwater resources is implicitly included in the constraints. Decision variables include the areas for different land uses, as well as the amounts of water supplied by the various sources. The decision variables, objective function, and constraint set in the programming model are described as follows:

\section{Decision Variables}

(1) Land uses:

$X_{i}$ : the total area of land use $i(\mathrm{ha}), i=1,2, \ldots, 8$, symbolizing land for agriculture, fish cultivation, industries, commerce, recreation, conservation, residence, and other uses, respectively.

$X_{1 j}$ : the area of land switched to land use $j$ from agricultural use. (ha)

$X_{2 j}$ : the area of land switched to land use $j$ from fish cultivation use. (ha)

$X_{8 j}$ : the area of land switched to land use $j$ from other uses. (ha)

(2) Water supplies

$Q_{s i}$ : the surface water consumption of land use $i\left(10^{4} \mathrm{~m}^{3} /\right.$ year $), i=1,2, \ldots, 8$.

$Q_{g i}$ : the groundwater consumption of land use $i\left(10^{4} \mathrm{~m}^{3} /\right.$ year $), i=1,2, \ldots, 8$.

$Q_{a i}$ : the water consumption supplied by alternative sources of land use $i\left(10^{4} \mathrm{~m}^{3} /\right.$ year $)$, $i=1,2, \ldots, 8$.

\section{Objective Function: Maximization of Total Net Benefit}

$$
\operatorname{Max} Z=\sum_{i=1}^{8} B_{i} X_{i}-\sum_{i=1}^{8} C_{s} Q_{s i}-\sum_{i=1}^{8} C_{g} Q_{g i}-\sum_{i=1}^{8} C_{a} Q_{a i}
$$


where

$B_{i}$ : unit value for land use $i\left(10^{4}\right.$ dollars/ha/year $), i=1,2, \ldots, 8$.

$C_{s}$ : unit cost of surface water (NT dollars $/ \mathrm{m}^{3}$ )

$C_{g}$ : unit cost of groundwater (NT dollars $/ \mathrm{m}^{3}$ )

$C_{a}$ : unit cost of water supplied by alternative sources (NT dollars $/ \mathrm{m}^{3}$ )

\section{Constraints}

1. Water demand constraints: water consumption should not exceed total available water supply for each land use.

$$
a_{i} X_{i} \leq Q_{s i}+Q_{g i}+Q_{a i} \quad \forall i
$$

where $a_{i}$ is the unit water demand for land use $i\left(\mathrm{~m}^{3} / \mathrm{ha} /\right.$ year $)$

2. Surface water supply constraint: total surface water consumption should not exceed the capacity of available surface water supply.

$$
\sum_{i=1}^{8} Q_{s i} \leq q_{s} \quad \forall i
$$

where $q_{s}$ is the total surface water supply capacity $\left(\mathrm{m}^{3} /\right.$ year)

3. Groundwater supply constraint: total groundwater consumption should not exceed the total amount of available groundwater supply (the safety yield of groundwater)

$$
\sum_{i=1}^{8} Q_{g i} \leq q_{g} \quad \forall i
$$

where $q_{g}$ is the total groundwater supply $\left(\mathrm{m}^{3} /\right.$ year $)$

4. Available land area constraints: sum of all land uses equals the total land area

$$
\sum_{i=1}^{8} X_{i}=x_{0}
$$

where $x_{0}$ is the total land area (ha)

5. Land area balance constraints:

$$
\begin{gathered}
X_{i}=x_{0 i}-\sum_{j=3}^{7} X_{i j} \quad i=1,2,8 \\
X_{i}=x_{0 i}+X_{1 i}+X_{2 i}+X_{8 i} \quad i=3,4,5,6,7
\end{gathered}
$$

where $x_{0 i}$ is the current area of land use $i$

6. Upper and lower limits of land uses:

$$
l x_{i} \leq X_{i} \leq u x_{i} \quad \forall i
$$

where $l x_{i}$ and $u x_{i}$ are the lower limit and upper limit of the area of land use $i$, respectively 7. Non-negative constraints:

$$
\text { all decision variables } \geq 0
$$




\section{System Parameters and Sources of Uncertainty}

All system parameters need to be calculated or estimated based on data collected from various sources. In this section, the approaches for deciding the values of the parameters will be described.

1. $x_{0 i}$, the current area of each land use current land use: statistics are listed in Table I. They indicate that most lands are currently used for agriculture and fish cultivation.

2. $a_{i}$, the unit water demand for each land use: The average values of unit water demand for the counties in Central Taiwan are used to calculate $a_{1}$ and those for all counties in Taiwan are used for $a_{2}$ and $a_{3} \cdot a_{4}$ is calculated using the formula: per capita residential water consumption in Taiwan in $1994 \times$ the population of the area $\times$ population density of the area. $a_{5}$ is estimated similarly to $a_{4}$, assuming that the population density of a commercial area is $50 \%$ that of a residential area. $a_{6}$ is assumed to be the same as $a_{5}$ because data are not available and only very small amounts of land are used for recreation in this area. $a_{7}$ is assumed to be zero because land for conservation in this area covers only coastal wind-shielding forests which consume negligible amounts of water. $a_{8}$ is assumed to be the average of $a_{1}, a_{2}, a_{5}, a_{6}$, and $a_{7} \cdot a_{3}$ and $a_{4}$ are not taken into account because industrial and residential areas can be easily identified and hence should not be referred to when estimating $a_{8}$ which corresponds to "other uses".

3. $B_{i}$, the unit monetary value for land use: $i$ the unit monetary value for each land use is estimated by combining the land's market price and the production value according to the land use. Most statistics are available, except for the production value of recreational land use. This is estimated by referring to the financial analysis of a recreational project in the vicinity, (the White Water Lake Recreation Project).

4. Unit water costs: $C_{s}$ is assumed to equal the unit price of potable water in Taiwan, which is NT\$ $9.0 / \mathrm{m}^{3}$. Groundwater in Taiwan is currently free, but charges for use are inevitable in the future. Furthermore, its unit price should be larger than that of potable water in the coastal areas suffering from land subsidence; hence $C_{g}$ is assumed to be twice the cost of surface water, $C_{s}$. Costs for developing alternative water supply sources include fixed and variant costs. In order to encourage the development and use of alternative water sources, the water's unit price should be less than that for potable water. In this model, for simplicity, $C_{a}$ is assumed to be $50 \% C_{s}$.

5. Water supply capacities: Based on the current plan for surface water development in this area, more surface water will be supplied by Chi-Chi and Jei-Fong Reservoirs in the year of 2011 and the surface water supply capacity $q_{s}$ is estimated at 495.6 million tons at that time. However, since water deficiency in the coming years is expected, more surface water development projects are currently planned and are being implemented.

TABLE I The Current Area and Corresponding Upper and Lower Limits of each Land Use.

\begin{tabular}{llcrr}
\hline$i$ & Land use & Lower limit (ha) & Current area $(\mathrm{ha})$ & Upper limit (ha) \\
\hline 1 & Agriculture & 7455.8 & 14922.5 & 14911.5 \\
2 & Fish cultivation & 2610.6 & 6526.4 & 6526.4 \\
3 & Industries & 2500.0 & 51.5 & 28990.5 \\
4 & Commerce & 14.6 & 14.6 & 146.0 \\
5 & Recreation & 123.1 & 123.1 & 29062.1 \\
6 & Residence & 164.8 & 164.8 & 494.4 \\
7 & Conservation & 578.3 & 578.3 & 29517.3 \\
8 & Others & 0 & 7501.1 & 7501.1 \\
& Total & & 29871.3 & \\
\hline
\end{tabular}


Hence, a $q_{s}$ larger than 495.6 million tons in 2011 is possible. The safety yield of groundwater $q_{g}$ in this area in 2011 has been estimated at 49.7 million tons by another project of the Water Resources Bureau in Taiwan. No capacity is specified for alternative water sources in this study.

6. The lower and upper limits of each land use: For industrial, residential, recreational, commercial, and conservation land uses, the lower limits are set according to their respective current areas or changes in light of future development. The lower limit for agricultural land use is set as either 0 or $50 \%$ of the current area. The lower limit for fish cultivation land use is set as either 0 or $40 \%$ of the current use based on fishing policy. The lower limit for "other" land uses is zero. The upper limits for agricultural, fish cultivation, and "other" land uses are set according to their respective current areas. The upper limits for industrial, recreational, and conservation land uses are the summation of the total area of current agricultural, fish cultivation, and "other" lands and their respective current areas. The upper limits for commercial and residential uses are set as 10 times and 3 times their respective current areas. All information is provided in Table II.

\section{Formulation of the GLP Model}

While examining the procedures for determining or estimating the parameter values stated above it is obvious that uncertainties in system parameters cannot be ignored. For example, many $a_{i}$ 's are estimated by using the average values calculated in a larger area, e.g., the whole of Taiwan or counties in Central Taiwan. Consequently, certain parameter values cannot be easily determined for each $a_{i}$. Moreover, the unit value for each land use $B_{i}$ is estimated by combining the land's market value and the production value according to the land use. Uncertainties may exist in both the land's market value and the production value. The unit water costs are also uncertain because $C_{s}$ may change in the future and the assumptions regarding $C_{g}$ and $C_{a}$ might not be correct. For these uncertainties, it is not easy or even not appropriate to describe them by probability distributions or membership functions of fuzzy sets. Modeling the parameters as intervals is a more reasonable method. When the system parameters can vary within their respective ranges or grey

TABLE II System Parameters of the Case Study.

\begin{tabular}{|c|c|c|c|c|c|c|c|}
\hline \multirow[b]{2}{*}{$i$} & & \multicolumn{3}{|c|}{$\underline{\text { Unit water demand } a_{i}^{ \pm}\left(m^{3} / \text { ha/year }\right)}$} & \multicolumn{3}{|c|}{ Unit value $B_{i}^{ \pm}\left(10^{3} N T \$ /\right.$ ha/year $)$} \\
\hline & & $a_{i}^{-}$ & $a_{i}^{M}$ & $a_{i}^{+}$ & $B_{i}^{-}$ & $B_{i}^{M}$ & $B_{i}^{+}$ \\
\hline 1 & Agriculture & 19772 & 20813 & 21854 & 27900 & 27985 & 28070 \\
\hline 2 & Fish cultivation & 56268 & 59229 & 62190 & 44800 & 44847 & 44890 \\
\hline 3 & Industries & 93864 & 98804 & 103744 & 337800 & 337863 & 337920 \\
\hline 4 & Commerce & 7893 & 8308 & 8723 & 537200 & 537214 & 537220 \\
\hline 5 & Recreation & 7893 & 8308 & 8723 & 98600 & 98609 & 98618 \\
\hline 6 & Residence & 15785 & 16616 & 17447 & 190500 & 190575 & 190650 \\
\hline 7 & Conservation & 0 & 0 & 0 & 15100 & 15125 & 15150 \\
\hline \multirow[t]{2}{*}{8} & Others & 19943 & 20993 & 22043 & 75400 & 75428 & 75450 \\
\hline & & \multicolumn{3}{|c|}{ Unit water cost $C_{*}^{ \pm}\left(N T \$ / m^{3}\right)$} & \multicolumn{3}{|c|}{ Water supply capacity $q_{*}^{ \pm}\left(10^{6} \mathrm{~m}^{3} /\right.$ year $)$} \\
\hline$*$ & & $C_{*}^{-}$ & $C_{*}^{M}$ & $C_{*}^{+}$ & $q_{*}^{-}$ & $q_{*}^{M}$ & $q_{*}^{+}$ \\
\hline$s$ & Surface water & 8.5 & 9 & 9.5 & 690 & 693.84 & 698 \\
\hline$g$ & Groundwater & 17 & 18 & 19 & 49 & 49.72 & 50.5 \\
\hline$a$ & Alternative & 4.25 & 4.5 & 4.75 & & & \\
\hline
\end{tabular}


intervals, the corresponding solutions for the objective function value and the decision variables will also vary within ranges. Thus, the optimization model becomes a grey linear programming (GLP) as follows.

$$
\operatorname{Max} Z^{ \pm}=\sum_{i=1}^{8} B_{i}^{ \pm} X_{i}^{ \pm}-\sum_{i=1}^{8} C_{s}^{ \pm} Q_{s i}^{ \pm}-\sum_{i=1}^{8} C_{g}^{ \pm} Q_{g i}^{ \pm}-\sum_{i=1}^{8} C_{a}^{ \pm} Q_{a i}^{ \pm}
$$

s.t.

$$
\begin{array}{ll}
a_{i}^{ \pm} X_{i}^{ \pm} \leq Q_{s i}^{ \pm}+Q_{g i}^{ \pm}+Q_{a i}^{ \pm} & \forall i \\
\sum_{i=1}^{8} Q_{s i}^{ \pm} \leq q_{s}^{ \pm} & \forall i \\
\sum_{i=1}^{8} Q_{g i}^{ \pm} \leq q_{g}^{ \pm} & \forall i \\
\sum_{i=1}^{8} X_{i}^{ \pm}=x_{0} & \\
X_{i}^{ \pm}=x_{0 i}-\sum_{j=3}^{7} X_{i j}^{ \pm} & \\
X_{i}^{ \pm}=x_{0 i}+X_{1 i}^{ \pm}+X_{2 i}^{ \pm}+X_{8 i}^{ \pm} & i=1,2,8 \\
l x_{i} \leq X_{i}^{ \pm} \leq u x_{i} & \forall i
\end{array}
$$

where the sign " \pm " indicates that the corresponding system parameter or decision variable is grey. $x_{0}$ and $x_{0 i}$ 's are constants instead of grey numbers in this example, assuming measurement errors are not taken into consideration. $l x_{i}$, and $u x_{i}$ are also assumed to be constant. The grey system parameters are estimated and listed in Table I.

In this GLP model some decision variables, $X_{i j}^{ \pm}$'s, are not shown in the objective function. Therefore difficulties will arise if traditional GLP algorithms are used to solve the problem. Under such circumstances, stable grey solutions can be obtained by using modified GLP algorithms. In the following, this problem will be formulated and solved by using modified GLP models. Moreover, to obtain more practical grey solutions, the formulation will be further modified and leads to a problem-oriented GLP model.

\section{Formulation of Modified GLP}

Formulation of a model using modified GLP algorithms is not unique. Assumptions regarding the bounds of system parameters and decision variables in the submodels need to be made. The rule is that these assumptions must be reasonable. In other words, only a mathematically and physically reasonable formulation with a good interpretation of the solutions can make GLP algorithms applicable [21].

The following is one set of modified GLP formulations based on specified assumptions with respect to the grey relationships between system parameters and decision variables: 


\section{Model 1}

Submodel 1:

$$
\operatorname{Max} Z^{+}=\sum_{i=1}^{8} B_{i}^{+} X_{i}^{+}-\sum_{i=1}^{8} C_{s}^{-} Q_{s i}^{-}-\sum_{i=1}^{8} C_{g}^{-} Q_{g i}^{-}-\sum_{i=1}^{8} C_{a}^{-} Q_{a i}^{-}
$$

s.t.

$$
\begin{array}{ll}
a_{i}^{-} X_{i}^{+}-Q_{s i}^{-}-Q_{g i}^{-}-Q_{a i}^{-} \leq 0 & \forall i \\
\sum_{i=1}^{8} Q_{s i}^{-} \leq q_{s}^{-} & \forall i \\
\sum_{i=1}^{8} Q_{g i}^{-} \leq q_{g}^{-} & \forall i \\
\sum_{i=1}^{8} X_{i}^{+}=x_{0} & \\
X_{i}^{+}+\sum_{j=3}^{7} X_{i j}=x_{0 i} & i=1,2,8 \\
X_{i}^{+}-X_{1 i}-X_{2 i}-X_{8 i}=x_{0 i} & i=3,4,5,6,7 \\
l x_{i} \leq X_{i}^{+} \leq u x_{i} & \forall i
\end{array}
$$

$Z_{\mathrm{opt}}^{+},\left(X_{i}^{+}\right)_{\mathrm{opt}},\left(Q_{s i}^{-}\right)_{\mathrm{opt}},\left(Q_{g i}^{-}\right)_{\mathrm{opt}}$, and $\left(Q_{a i}^{-}\right)_{\mathrm{opt}}$ for all $i$ can be obtained from this submodel.

Submodel 2:

$$
\operatorname{Max} Z^{-}=\sum_{i=1}^{8} B_{i}^{-} X_{i}^{-}-\sum_{i=1}^{8} C_{s}^{+} Q_{s i}^{+}-\sum_{i=1}^{8} C_{g}^{+} Q_{g i}^{+}-\sum_{i=1}^{8} C_{a}^{+} Q_{a i}^{+}
$$

s.t.

$$
\begin{array}{ll}
a_{i}^{+} X_{i}^{-}-Q_{s i}^{+}-Q_{g i}^{+}-Q_{a i}^{+} \leq 0 & \forall i \\
\sum_{i=1}^{8} Q_{s i}^{+} \leq q_{s}^{+} & \forall i \\
\sum_{i=1}^{8} Q_{g i}^{+} \leq q_{g}^{+} & \forall i \\
\sum_{i=1}^{8} X_{i}^{-}=x_{0} & \\
X_{i}^{-}+\sum_{j=3}^{7} X_{i j}=x_{0 i} & \\
X_{i}^{-}-X_{1 i}-X_{2 i}-X_{8 i}=x_{0 i} & i=3,4,5,6,7 \\
l x_{i} \leq X_{i}^{-} \leq u x_{i} & \forall i \\
X_{i}^{-} \leq\left(X_{i}^{+}\right)_{\mathrm{opt}} & \forall i \\
Q_{s i}^{+} \geq\left(Q_{s i}^{-}\right)_{\mathrm{opt}} & \forall i \\
Q_{g i}^{+} \geq\left(Q_{g i}^{-}\right)_{\mathrm{opt}} & \forall i \\
Q_{a i}^{+} \geq\left(Q_{a i}^{-}\right)_{\mathrm{opt}} & \forall i
\end{array}
$$

$Z_{\mathrm{opt}}^{-},\left(X_{i}^{-}\right)_{\mathrm{opt}},\left(Q_{s i}^{+}\right)_{\mathrm{opt}},\left(Q_{g i}^{+}\right)_{\mathrm{opt}}$, and $\left(Q_{a i}^{+}\right)_{\mathrm{opt}}$ for all $i$ can be obtained from this submodel. 
In this set of submodels, $\quad \mathbf{X}_{\mathbf{p}}=\left\{X_{i} \mid \forall i\right\}, \quad \mathbf{X}_{\mathbf{n}}=\left\{Q_{s i}, Q_{g i}, Q_{a i} \mid \forall i\right\}, \quad \mathbf{X}_{\mathbf{z}}=\left\{X_{i j} \mid\right.$ $i=1,2,8 ; j=3,4,5,6,7\}$. Some corresponding bounds of system parameters are assumed. All decision variables in $\mathbf{X}_{\mathbf{n}}$ are not fully greylized because their bounds in each submodel cannot be easily determined. For example, if smaller $X_{i j}$ 's and hence $X_{i j}^{-}$'s are assumed in (26) and larger $X_{i j}$ 's and hence $X_{i j}^{+}$'s are assumed in (27), contradiction will occur because only one bound for a decision variable can exist in a submodel. Since $X_{i j}$ 's are not fully greylized, their corresponding resulting solutions cannot form and should not be interpreted as stable grey intervals.

Note that we can conclude $\left(X_{i}^{-}\right)_{\mathrm{opt}}=\left(X_{i}^{+}\right)_{\mathrm{opt}}$ from (25), (33), and (37), i.e., $\left(X_{i}^{ \pm}\right)_{\mathrm{opt}}$ will be constants instead of grey numbers. This will make the resulting grey solutions less applicable.

To overcome this shortcoming, the modified GLP model can be further modified based on specific conditions of this problem, which leads to a problem-oriented GLP model.

\section{Formulation of Problem-Oriented GLP}

Model 1 in the preceeding section will generate non-grey solutions for $X_{i}^{ \pm}$. However, ranges for $\left(X_{i}^{ \pm}\right)_{\text {opt }}$ as system parameters can vary within ranges which might be desired according to the preferences of decision makers. This situation of non-grey $\left(X_{i}^{ \pm}\right)_{\text {opt }}$ exists because the equality constraints (25) and (33) are accompanied by the inequality constraint (37). Therefore, all $X_{i}^{\prime}$ 's in the first submodel are $X_{i}^{+}$'s and all $X_{i}$ 's in the second submodel are $X_{i}^{-}$'s. If we could formulate a set of submodels in which some $X_{i}^{-}$'s and some $X_{i}^{+}$'s are in each submodel, they may result in ranges for $\left(X_{i}^{ \pm}\right)_{\text {opt }}$. Note that the reason for the formulation of Model 1 is to maintain the stability of its resulting grey solutions. This stability must be held in any further formulation modification.

Through observing $B_{i}^{ \pm}$, the corresponding coefficients of $X_{i}^{ \pm}$in the objective function, it was found that some $B_{i}^{ \pm}$'s are much larger than others. If $X_{i}$ 's are larger, i.e., more land is used, for those with larger $B_{i}^{ \pm}$'s whereas $X_{i}$ 's are smaller, i.e., less land is used, for those with smaller $B_{i}^{ \pm}$'s, a larger total benefit may be achieved. Based on the fact that any $B_{i}^{ \pm} \in\left\{B_{i}^{ \pm} \mid i=3,4,5,6\right\}$ is larger than a $B_{i}^{ \pm} \in\left\{B_{i}^{ \pm} \mid i=1,2,7,8\right\}$, the following set of submodels is formulated:

Model 2

Submodel 1:

$\operatorname{Max} Z^{+}=\sum_{i=3}^{6} B_{i}^{+} X_{i}^{+}+\sum_{i=1,2,7,8} B_{i}^{+} X_{i}^{-}-\sum_{i=1}^{8} C_{s}^{-} Q_{s i}^{-}-\sum_{i=1}^{8} C_{g}^{-} Q_{g i}^{-}-\sum_{i=1}^{8} C_{a}^{-} Q_{a i}^{-}$

s.t.

$$
\begin{array}{ll}
a_{i}^{-} X_{i}^{+}-Q_{s i}^{-}-Q_{g i}^{-}-Q_{a i}^{-} \leq 0 & i=3,4,5,6 \\
a_{i}^{+} X_{i}^{-}-Q_{s i}^{-}-Q_{g i}^{-}-Q_{a i}^{-} \leq 0 & i=1,2,7,8 \\
\sum_{i=1}^{8} Q_{s i}^{-} \leq q_{s}^{-} & \forall i \\
\sum_{i=1}^{8} Q_{g i}^{-} \leq q_{g}^{-} & \forall i \\
\sum_{i=3}^{6} X_{i}^{+}+\sum_{i=1,2,7,8} X_{i}^{-}=x_{0} &
\end{array}
$$




$$
\begin{array}{ll}
X_{i}^{+}-X_{1 i}-X_{2 i}-X_{8 i}=x_{0 i} & i=3,4,5,6 \\
X_{i}^{-}+\sum_{j=3}^{7} X_{i j}=x_{0 i} & i=1,2,8 \\
X_{7}^{-}-X_{17}-X_{27}-X_{87}=x_{07} & \\
l x_{i} \leq X_{i}^{+} \leq u x_{i} & i=3,4,5,6 \\
l x_{i} \leq X_{i}^{-} \leq u x_{i} & i=1,2,7,8
\end{array}
$$

$Z_{\mathrm{opt}}^{+} ;\left(X_{i}^{+}\right)_{\mathrm{opt}}$ for $i=3,4,5,6 ;\left(X_{i}^{-}\right)_{\mathrm{opt}}$ for $i=1,2,7,8 ;\left(Q_{s i}^{-}\right)_{\mathrm{opt}},\left(Q_{\mathrm{gi}}^{-}\right)_{\mathrm{opt}}$, and $\left(Q_{a i}^{-}\right)_{\mathrm{opt}}$ for all $i$ can be obtained from this submodel.

\section{Submodel 2:}

$\operatorname{Max} Z^{-}=\sum_{i=3}^{6} B_{i}^{-} X_{i}^{-}+\sum_{i=1,2,7,8} B_{i}^{-} X_{i}^{+}-\sum_{i=1}^{8} C_{s}^{+} Q_{s i}^{+}-\sum_{i=1}^{8} C_{g}^{+} Q_{g i}^{+}-\sum_{i=1}^{8} C_{a}^{+} Q_{a i}^{+}$

s.t.

$$
\begin{array}{ll}
a_{i}^{+} X_{i}^{-}-Q_{s i}^{+}-Q_{g i}^{+}-Q_{a i}^{+} \leq 0 & i=3,4,5,6 \\
a_{i}^{-} X_{i}^{+}-Q_{s i}^{+}-Q_{g i}^{+}-Q_{a i}^{+} \leq 0 & i=1,2,7,8 \\
\sum_{i=1}^{8} Q_{s i}^{+} \leq q_{s}^{+} & \forall i \\
\sum_{i=1}^{8} Q_{g i}^{+} \leq q_{g}^{+} & \forall i \\
\sum_{i=3}^{6} X_{i}^{-}+\sum_{i=1,2,7,8} X_{i}^{+}=x_{0} & \\
X_{i}^{-}-X_{1 i}-X_{2 i}-X_{8 i}=x_{0 i} & i=3,4,5,6, \\
X_{i}^{+}+\sum_{j=3}^{7} X_{i j}=x_{0 i} & i=1,2,8 \\
X_{7}^{+}-X_{17}-X_{27}-X_{87}=x_{07} & \\
l x_{i} \leq X_{i}^{-} \leq u x_{i} & i=3,4,5,6 \\
l x_{i} \leq X_{i}^{+} \leq u x_{i} & i=1,2,7,8 \\
X_{i}^{-} \leq\left(X_{i}^{+}\right)_{\mathrm{opt}} & i=3,4,5,6 \\
X_{i}^{+} \geq\left(X_{i}^{-}\right)_{\mathrm{opt}} & i=1,2,7,8 \\
Q_{s i}^{+} \geq\left(Q_{s i}^{-}\right)_{\mathrm{opt}} & \forall i \\
Q_{g i}^{+} \geq\left(Q_{g i}^{-}\right)_{\mathrm{opt}} & \forall i \\
Q_{a i}^{+} \geq\left(Q_{a i}^{-}\right)_{\mathrm{opt}} &
\end{array}
$$

$Z_{\mathrm{opt}}^{-} ;\left(X_{i}^{-}\right)_{\mathrm{opt}}$ for $i=3,4,5,6 ;\left(X_{i}^{+}\right)_{\mathrm{opt}}$ for $i=1,2,7,8,\left(Q_{s i}^{+}\right)_{\mathrm{opt}},\left(Q_{g i}^{+}\right)_{\mathrm{opt}}$, and $\left(Q_{a i}^{+}\right)_{\mathrm{opt}}$ for all $i$ can be obtained from this submodel. 
Proof of Stability From (41) to (67),

$$
\begin{aligned}
Z_{\mathrm{opt}}^{+}= & \sum_{i=3}^{6} B_{i}^{+}\left(X_{i}^{+}\right)_{\mathrm{opt}}+\sum_{i=1,2,7,8} B_{i}^{+}\left(X_{i}^{-}\right)_{\mathrm{opt}}-\sum_{i=1}^{8} C_{s}^{-}\left(Q_{s i}^{-}\right)_{\mathrm{opt}}-\sum_{i=1}^{8} C_{g}^{-}\left(Q_{g i}^{-}\right)_{\mathrm{opt}} \\
& -\sum_{i=1}^{8} C_{a}^{-}\left(Q_{a i}^{-}\right)_{\mathrm{opt}} \\
Z_{\mathrm{opt}}^{-}= & \sum_{i=3}^{6} B_{i}^{-}\left(X_{i}^{-}\right)_{\mathrm{opt}}+\sum_{i=1,2,7,8} B_{i}^{-}\left(X_{i}^{+}\right)_{\mathrm{opt}}-\sum_{i=1}^{8} C_{s}^{+}\left(Q_{s i}^{+}\right)_{\mathrm{opt}}-\sum_{i=1}^{8} C_{g}^{+}\left(Q_{g i}^{+}\right)_{\mathrm{opt}} \\
& -\sum_{i=1}^{8} C_{a}^{+}\left(Q_{a i}^{+}\right)_{\mathrm{opt}}
\end{aligned}
$$

and for $B_{i} \in\left[B_{i}^{-}, B_{i}^{+}\right], \quad C_{s} \in\left[C_{s}^{-}, C_{s}^{+}\right], \quad C_{g} \in\left[C_{g}^{-}, C_{g}^{+}\right], \quad C_{a} \in\left[C_{a}^{-}, C_{a}^{+}\right], \quad X_{i} \in\left[\left(X_{i}^{-}\right)_{\mathrm{opt}}\right.$, $\left.\left(X_{i}^{+}\right)_{\mathrm{opt}}\right], Q_{s i} \in\left[\left(Q_{s i}^{-}\right)_{\mathrm{opt}},\left(Q_{s i}^{+}\right)_{\mathrm{opt}}\right], Q_{g i} \in\left[\left(Q_{g i}^{-}\right)_{\mathrm{opt}},\left(Q_{g i}^{+}\right)_{\mathrm{opt}}\right], Q_{a i} \in\left[\left(Q_{a i}^{-}\right)_{\mathrm{opt}},\left(Q_{a i}^{+}\right)_{\mathrm{opt}}\right]$ for all $i$,

$$
\begin{aligned}
Z^{ \pm}=\sum_{i=3}^{6} B_{i} & X_{i}+\sum_{i=1,2,7,8} B_{i} X_{i}-\sum_{i=1}^{8} C_{s} Q_{s i}-\sum_{i=1}^{8} C_{g} Q_{g i}-\sum_{i=1}^{8} C_{a} Q_{a i} \\
Z_{\mathrm{opt}}^{+}-Z^{ \pm}= & \sum_{i=3}^{6}\left[B_{i}^{+}\left(X_{i}^{+}\right)_{\mathrm{opt}}-B_{i} X_{i}\right]+\sum_{i=1,2,7,8}\left[B_{i}^{+}\left(X_{i}^{-}\right)_{\mathrm{opt}}-B_{i} X_{i}\right] \\
& +\sum_{i=1}^{8}\left[C_{s} Q_{s i}-C_{s}^{-}\left(Q_{s i}^{-}\right)_{\mathrm{opt}}\right]+\sum_{i=1}^{8}\left[C_{g} Q_{g i}-C_{g}^{-}\left(Q_{g i}^{-}\right)_{\mathrm{opt}}\right] \\
& +\sum_{i=1}^{8}\left[C_{a} Q_{a i}-C_{a}^{-}\left(Q_{a i}^{-}\right)_{\mathrm{opt}}\right]=\sum_{i=3}^{6}\left[B_{i}^{+}\left(X_{i}^{+}\right)_{\mathrm{opt}}-B_{i} X_{i}\right] \\
& +\sum_{i=1,2,7,8}\left[B_{i}^{+}\left(X_{i}^{-}\right)_{\mathrm{opt}}-B_{i} X_{i}\right]+\mathrm{M}_{1}+\mathrm{M}_{2}+\mathrm{M}_{3}
\end{aligned}
$$

where $\mathrm{M}_{1}=\sum_{i=1}^{8}\left[C_{s} Q_{s i}-C_{s}^{-}\left(Q_{s i}^{-}\right)_{\mathrm{opt}}\right] \geq 0, \mathrm{M}_{2}=\sum_{i=1}^{8}\left[C_{g} Q_{g i}-C_{g}^{-}\left(Q_{g i}^{-}\right)_{\mathrm{opt}}\right] \geq 0, \mathrm{M}_{3}=$ $\sum_{i=1}^{8}\left[C_{a} Q_{a i}-C_{a}^{-}\left(Q_{a i}^{-}\right)_{\mathrm{opt}}\right] \geq 0$

and

$$
\begin{aligned}
\sum_{i=3}^{6}[ & \left.B_{i}^{+}\left(X_{i}^{+}\right)_{\mathrm{opt}}-B_{i} X_{i}\right]+\sum_{i=1,2,7,8}\left[B_{i}^{+}\left(X_{i}^{-}\right)_{\mathrm{opt}}-B_{i} X_{i}\right] \\
\geq & \sum_{i=3}^{6}\left\{B_{i}^{+}\left[\left(X_{i}^{-}\right)_{\mathrm{opt}}+\left(\Delta X_{i}\right)_{\mathrm{opt}}\right]-B_{i}^{+}\left[\left(X_{i}^{-}\right)_{\mathrm{opt}}+\Delta X_{i}^{A}\right]\right\} \\
& +\sum_{i=1,2,7,8}\left\{B_{i}^{+}\left(X_{i}^{-}\right)_{\mathrm{opt}}-B_{i}^{+}\left[\left(X_{i}^{-}\right)_{\mathrm{opt}}+\Delta X_{i}^{B}\right]\right\} \\
= & \sum_{i=3}^{6}\left\{B_{i}^{+}\left[\left(\Delta X_{i}\right)_{\mathrm{opt}}-\Delta X_{i}^{A}\right]\right\}-\sum_{i=1,2,7,8} B_{i}^{+} \Delta X_{i}^{B}
\end{aligned}
$$

From the constraint $\sum_{i=1}^{8} X_{i}=x_{0}$ and corresponding ones (43) and (54), we can have

$$
\sum_{i=1}^{8}\left(\Delta X_{i}\right)_{\mathrm{opt}}=\sum_{i=3}^{6} \Delta X_{i}^{A}+\sum_{i=1,2,7,8} \Delta X_{i}^{B}
$$


Moreover, given that $\operatorname{Min}\left\{B_{i}, i=3,4,5,6\right\}=B_{m 1} \geq B_{M 2}=\operatorname{Max}\left\{B_{i}, i=1,2,7,8\right\}$

$$
\begin{aligned}
\sum_{i=3}^{6}\left\{B_{i}^{+}\left[\left(\Delta X_{i}\right)_{\mathrm{opt}}-\Delta X_{i}^{A}\right]\right\}-\sum_{i=1,2,7,8} B_{i}^{+} \Delta X_{i}^{B} \\
\geq \sum_{i=3}^{6}\left\{B_{m 1}\left[\left(\Delta X_{i}\right)_{\mathrm{opt}}-\Delta X_{i}^{A}\right]\right\}-\sum_{i=1,2,7,8} B_{M 2} \Delta X_{i}^{B} \\
\quad \geq \sum_{i=3}^{6}\left\{B_{m 1}\left[\left(\Delta X_{i}\right)_{\mathrm{opt}}-\Delta X_{i}^{A}\right]\right\}-\sum_{i=1,2,7,8} B_{m 1} \Delta X_{i}^{B} \\
=B_{m 1} \cdot\left[\sum_{i=1}^{8}\left(\Delta X_{i}\right)_{\mathrm{opt}}-\left(\sum_{i=3}^{6} \Delta X_{i}^{A}+\sum_{i=1,2,7,8} \Delta X_{i}^{B}\right)\right]=0
\end{aligned}
$$

Hence, $Z_{\text {opt }}^{+}-Z^{ \pm} \geq 0+\mathrm{M}_{1}+\mathrm{M}_{2}+\mathrm{M}_{3} \geq 0$.

Similarly, we can prove that $Z^{ \pm}-Z_{\text {opt }}^{-} \geq 0$.

As a consequence, for $B_{i} \in\left[B_{i}^{-}, B_{i}^{+}\right], C_{s} \in\left[C_{s}^{-}, C_{s}^{+}\right], C_{g} \in\left[C_{g}^{-}, C_{g}^{+}\right], C_{a} \in\left[C_{a}^{-}, C_{a}^{+}\right]$, $X_{i} \in\left[\left(X_{i}^{-}\right)_{\mathrm{opt}},\left(X_{i}^{+}\right)_{\mathrm{opt}}\right], \quad Q_{s i} \in\left[\left(Q_{s i}^{-}\right)_{\mathrm{opt}},\left(Q_{s i}^{+}\right)_{\mathrm{opt}}\right], \quad Q_{g i} \in\left[\left(Q_{g i}^{-}\right)_{\mathrm{opt}},\left(Q_{g i}^{+}\right)_{\mathrm{opt}}\right], \quad Q_{a i} \in\left[\left(Q_{a i}^{-}\right)_{\mathrm{opt}}\right.$, $\left.\left(Q_{a i}^{+}\right)_{\text {opt }}\right]$ for all $i$, we can prove $Z^{ \pm} \in\left[Z_{\text {opt }}^{-}, Z_{\text {opt }}^{+}\right]$, i.e., stability holds.

As in Model 1, $X_{i j}$ 's are not fully greylized in this set of submodels. Hence, the solutions obtained from the two submodels cannot be interpreted as grey intervals. Further modifications can cause some of $X_{i j}$ 's able to form stable grey intervals. There are many possible sets of stable grey intervals in the solution space and a GP model's purpose is just to identify one set of them. By adjusting the grey relationships between system parameters and decision variables, different sets of stable grey intervals can be obtained. For example, another set of submodels, Model 3, can be formulated by changing the following from Model 2:

1. Let all $X_{i j}$ 's for $i=1,2,8$ and $j=3,4,5,6$ be $X_{i j}^{+}$'s in the first submodel and $X_{i j}^{-}$'s in the second one while keeping $X_{17}, X_{27}$, and $X_{87}$ not fully greylized.

2. In the second submodel, add constraints similar to (63) to let $X_{i j}^{-} \leq\left(X_{i j}^{+}\right)_{\mathrm{opt}}$ for $i=1,2,8$ and $j=3,4,5,6$ solved from the first submodel.

Since $X_{i j}$ 's are not shown in the objective function, their values will not influence the objective function values. Therefore, the stability is maintained as long as the two submodels are both feasible.

\section{Grey Solutions and Sensitivity}

With the system parameters listed in Table I and II, three GLP models are solved. Note that in Table I the lower bounds for agricultural and fish cultivation land use are set as $50 \%$ and $40 \%$ of their current areas, respectively. Also note that the surface water supply capacity $q_{s}^{ \pm}$in Table II is $140 \%$ of the estimated one because a $q_{s}^{ \pm}$equaling 495.6 million $\mathrm{m}^{3}$ per year cannot make the optimization problem feasible and a $q_{s}^{ \pm}$larger than that number is possible based on preceeding analysis. More surface water sources need to be developed; otherwise the integrated development of this area will be problematic. Also, it is assumed that alternative water sources will be developed only for fish cultivation and industries. Therefore, only $Q_{a 2}$ and $Q_{a 3}$ are considered.

When solving Model 1 using the system parameters in Table I and II, it was found that the second submodel cannot be feasible because the degree of greyness of $a_{i}^{ \pm}$'s is too 
high $(=0.05)$. It was discussed in the preceeding that constraints (25), (33) and (37) will make $\left(X_{i}^{-}\right)_{\text {opt }}$ solved from the second submodel equal to $\left(X_{i}^{+}\right)_{\mathrm{opt}}$ solved from the first submodel for all $i$. Therefore, a set of feasible solutions for all decision variables cannot be easily obtained if $a_{i}^{-}$in the second submodel is too small relative to $a_{i}^{+}$in the first submodel. After extensive tests, 0.006 was found to be the maximum degree of greyness for $a_{i}^{ \pm}$'s from which feasible solutions can be obtained. The grey solutions are listed in Table III. The variables of $\left(X_{i j}\right)_{\text {opt }}$ are not included because they are not fully greylized in the submodels and hence cannot generate grey intervals.

The grey solutions offer information regarding how optimum system performance and decision variable values can change as the system parameters vary within grey intervals. For example, the solutions in Table III can be interpreted as follows: Given the ranges of

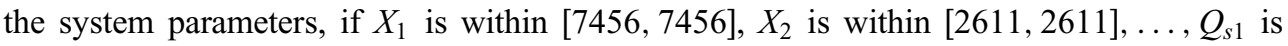
within [154245466, 156107583], $Q_{s 2}$ is within [153693133, 155548583], .., the system performance will be within [3044856, 3047350] million NT dollars.

The solutions indicate that all transferable lands currently in the categories of agriculture, fish cultivation, and "others" will be used for other purposes. Increases in land for industries, commerce, recreation, and residence are significant. Land area for conservation remains the same. Ranges for most $Q_{s i}$ 's and some $Q_{g i}$ 's can be observed. It is clear that industries will consume more surface water and groundwater than any other user. In addition to industries, groundwater may also be needed for recreation and residences but that amount is small in comparison to the water needs of industries. Unlike the current situation, no groundwater will be used for fish cultivation based on the optimum schemes. For alternative water sources, the demands for both fish cultivation and industries are zero based on the assumed costs.

Although grey solutions for the system performance and some $Q_{s i}$ 's and $Q_{g i}$ 's can be identified from Model 1, no grey solutions for $X_{i}$ 's can be obtained, so that the set of grey solutions is not very applicable. Through solving Model 2, the problem-oriented GLP model modified from Model 1, grey solutions for $X_{i}$ 's as well as other decision variables can be found. Table IV lists the sets of grey solutions from Model 2 with the degrees of greyness of $a_{i}^{ \pm}$'s equaling 0.05 and 1.0. Distribution of areas for various land uses is similar to that solved from Model 1. As the ranges of system parameters become larger, i.e., their degrees of greyness become higher, larger $Z_{\mathrm{opt}}^{+}$and smaller $Z_{\text {opt }}^{-}$will be achieved and hence the degree of greyness for the system performance is also higher. Similar situations can also be observed for the decision variable values. However, for some $Q_{s i}$ 's and $Q_{g i}$ 's, grey solutions change considerably because scales of $a_{i}^{ \pm}$'s differ significantly.

TABLE III Grey Solutions from Model 1 with $\operatorname{deg}\left(a_{i}^{ \pm}\right)=0.006$.

\begin{tabular}{|c|c|c|c|c|c|c|c|c|c|}
\hline \multicolumn{10}{|c|}{$Z_{\text {opt }}^{+}=3047350$ million NT\$, $Z_{\text {opt }}^{-}=3044856$ million NT\$ } \\
\hline$i$ & $X_{i}^{-}$ & $X_{i}^{+}$ & $\%^{*}$ & $Q_{s i}^{-}$ & $Q_{s i}^{+}$ & $Q_{g i}^{-}$ & $Q_{g i}^{+}$ & $Q_{a i}^{-}$ & $Q_{a i}^{+}$ \\
\hline 1 & 7456 & 7456 & 25.0 & 154245466 & 156107583 & 0 & 0 & & \\
\hline 2 & 2611 & 2611 & 8.7 & 153693133 & 155548583 & 0 & 0 & 0 & 0 \\
\hline 3 & 2982 & 2982 & 10.0 & 243823938 & 247359036 & $49 \times 10^{6}$ & $49 \times 10^{6}$ & 0 & 0 \\
\hline 4 & 146 & 146 & 0.5 & 1205690 & 1220246 & 0 & 0 & & \\
\hline 5 & 15605 & 15605 & 52.2 & 128866112 & 129598890 & 0 & 822950 & & \\
\hline 6 & 494 & 494 & 1.7 & 8165661 & 8165661 & 0 & 98579 & & \\
\hline 7 & 578 & 578 & 1.9 & 0 & 0 & 0 & 0 & & \\
\hline 8 & 0 & 0 & 0.0 & 0 & 0 & 0 & 0 & & \\
\hline
\end{tabular}

*Percentage of $X_{i}^{M}$. 
TABLE IV Grey Solutions from Model 2 with $\operatorname{deg}\left(a_{i}^{ \pm}\right)=0.05$ and 0.1 .

\begin{tabular}{|c|c|c|c|c|c|c|c|c|c|}
\hline$i$ & $X_{i}^{-}$ & $X_{i}^{+}$ & $\%^{*}$ & $Q_{s i}^{-}$ & $Q_{s i}^{+}$ & $Q_{g i}^{-}$ & $Q_{g i}^{+}$ & $Q_{a i}^{-}$ & $Q_{a i}^{+}$ \\
\hline \multicolumn{10}{|c|}{$\operatorname{deg}\left(a_{i}^{ \pm}\right)=0.05, Z_{o p t}^{+}=3052172$ million NT\$, $Z_{\mathrm{opt}}^{-}=2930133$ million NT\$ } \\
\hline 1 & 7456 & 7970 & 25.8 & 162935351 & 162935351 & 0 & 0 & & \\
\hline 2 & 2611 & 2885 & 9.2 & 162351901 & 162351901 & 0 & 0 & 0 & 0 \\
\hline 3 & 2716 & 3002 & 9.6 & 232753504 & 232753504 & $49 \times 10^{6}$ & $49 \times 10^{6}$ & 0 & 0 \\
\hline 4 & 146 & 146 & 0.5 & 1152320 & 1273616 & 0 & 0 & & \\
\hline 5 & 15081 & 15585 & 51.3 & 123002722 & 130059930 & 0 & $1.5 \times 10^{6}$ & & \\
\hline 6 & 494 & 494 & 1.7 & 7804203 & 8625698 & 0 & 0 & & \\
\hline 7 & 578 & 578 & 1.9 & 0 & 0 & 0 & 0 & & \\
\hline 8 & 0 & 0 & & 0 & 0 & 0 & 0 & & \\
\hline \multicolumn{10}{|c|}{$\operatorname{deg}\left(a_{i}^{ \pm}\right)=0.1, Z_{\text {opt }}^{+}=3070640$ million NT\$, $Z_{\mathrm{opt}}^{-}=2760054$ million NT\$ } \\
\hline 1 & 7456 & 9113 & 27.7 & 170694177 & 170694177 & 0 & 0 & & \\
\hline 2 & 2611 & 3191 & 9.7 & 170082944 & 170082944 & 0 & 0 & 0 & 0 \\
\hline 3 & 2519 & 3079 & 9.4 & 273785806 & 273785806 & 0 & 0 & 0 & 0 \\
\hline 4 & 146 & 146 & 0.5 & 0 & 242594 & 1091671 & 1091671 & & \\
\hline 5 & 13521 & 15507 & 48.6 & 75437073 & 81551489 & 40514873 & 42014873 & & \\
\hline 6 & 494 & 494 & 1.7 & 0 & 1642990 & 7393455 & 7393455 & & \\
\hline 7 & 578 & 887 & 2.5 & 0 & 0 & 0 & 0 & & \\
\hline 8 & 0 & 0 & 0 & 0 & 0 & 0 & 0 & & \\
\hline
\end{tabular}

*Percentage of $X_{i}^{M}$.

If grey solutions for $X_{i j}$ 's are desired, Model 3 can be employed. The resulting grey solutions for all decision variables except $X_{17}, X_{27}$, and $X_{87}$ are listed in Table V. Some of the decision variable values solved from the second submodel differ from those of Model 2. The worst optimum system performance is smaller than that obtained from Model 2 because more constraints are applied to this maximization problem. The solutions for $X_{i j}$ 's (except $X_{17}, X_{27}$, and $X_{87}$ ) can be interpreted as stable grey intervals. Note that for given values of $X_{i}$ 's, the solution set for $X_{i j}$ 's is not unique (8 equations, 21 variables). The grey intervals presented herein are also not unique.

TABLE V Grey Solutions from Model 3 with $\operatorname{deg}\left(a_{i}^{ \pm}\right)=0.05$.

\begin{tabular}{|c|c|c|c|c|c|c|c|c|c|}
\hline \multicolumn{10}{|c|}{$Z_{o p t}^{+}=3052172$ million NT\$, $Z_{\text {opt }}^{-}=2926474$ million NT\$ } \\
\hline$i$ & $X_{i}^{-}$ & $X_{i}^{+}$ & $\% *$ & $Q_{s i}^{-}$ & $Q_{s i}^{+}$ & $Q_{g i}^{-}$ & $Q_{g i}^{+}$ & $Q_{a i}^{-}$ & $Q_{a i}^{+}$ \\
\hline 1 & 7456 & 7684 & 25.3 & 162935351 & 162935351 & 0 & 0 & & \\
\hline 2 & 2611 & 2885 & 9.2 & 162351901 & 162351901 & 0 & 0 & 0 & 0 \\
\hline 3 & 2716 & 3002 & 9.6 & 232753504 & 232753504 & $49 \times 10^{6}$ & $49 \times 10^{6}$ & 0 & 0 \\
\hline 4 & 146 & 146 & 0.5 & 1152320 & 1273616 & 0 & 0 & & \\
\hline 5 & 15081 & 15585 & 51.3 & 123002722 & 130059930 & 0 & $1.5 \times 10^{6}$ & & \\
\hline 6 & 494 & 494 & 1.7 & 7804203 & 8625698 & 0 & 0 & & \\
\hline 7 & 578 & 864 & 2.4 & 0 & 0 & 0 & 0 & & \\
\hline \multirow[t]{2}{*}{8} & 0 & 0 & 0.0 & 0 & 0 & 0 & 0 & & \\
\hline & \multicolumn{2}{|c|}{$i=1$} & \multicolumn{2}{|c|}{$i=2$} & \multicolumn{2}{|c|}{$i=8$} & & & \\
\hline$j$ & $X_{i j}^{-}$ & $\overline{X_{i j}^{+}}$ & $X_{i j}^{-}$ & $\overline{X_{i j}^{+}}$ & $X_{i j}^{-}$ & $\overline{X_{i j}^{+}}$ & & & \\
\hline 3 & 0 & 0 & 0 & 0 & 2664 & 2950 & & & \\
\hline 4 & 0 & 0 & 0 & 0 & 131 & 131 & & & \\
\hline 5 & 7227 & 7456 & 3641 & 3916 & 4090 & 4090 & & & \\
\hline 6 & 0 & 0 & 0 & 0 & 330 & 330 & & & \\
\hline
\end{tabular}

*Percentage of $X_{i}^{M}$. 


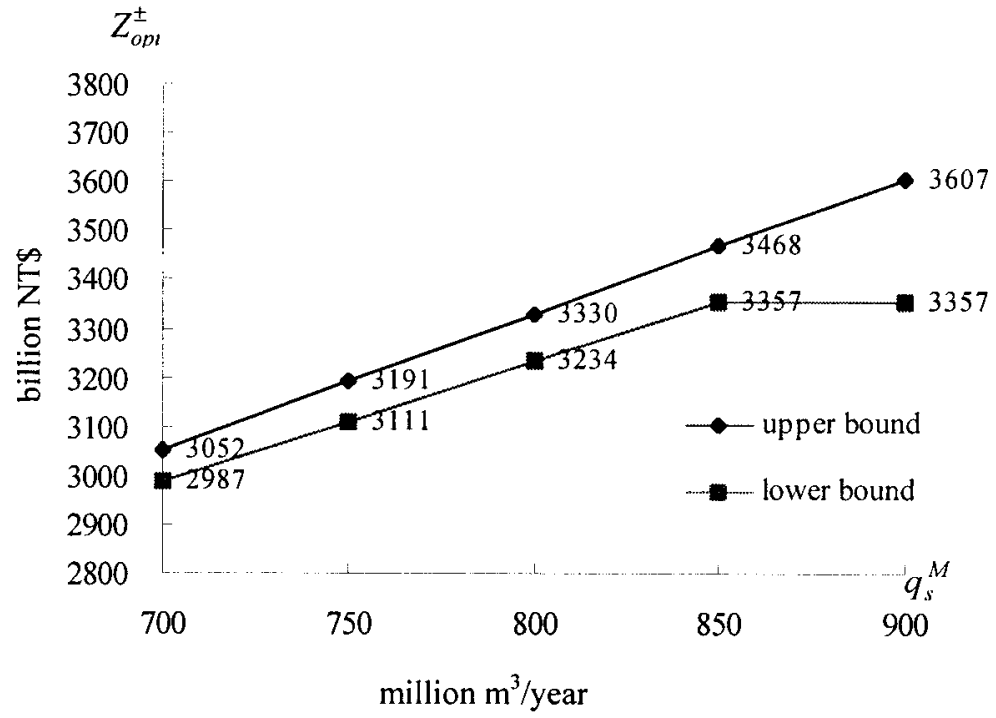

FIGURE 3 The optimum system performance $Z_{\mathrm{opt}}^{ \pm}$corresponding to surface water supply capacity $q_{s}^{M}$ where $q_{s}^{ \pm}=\left[q_{s}^{M}-10, q_{s}^{M}+10\right]$.

There can be many scenarios for a development plan. For example, upper and lower bounds of each land use may change, as will the corresponding different optimum schemes of land distribution and water consumption. The GLP algorithms presented in this study can offer decision makers information regarding how the optimum system performance and decision variable values can vary as the system parameters change within their respective ranges. The variation trend ranges can be known, for all development plans, without the

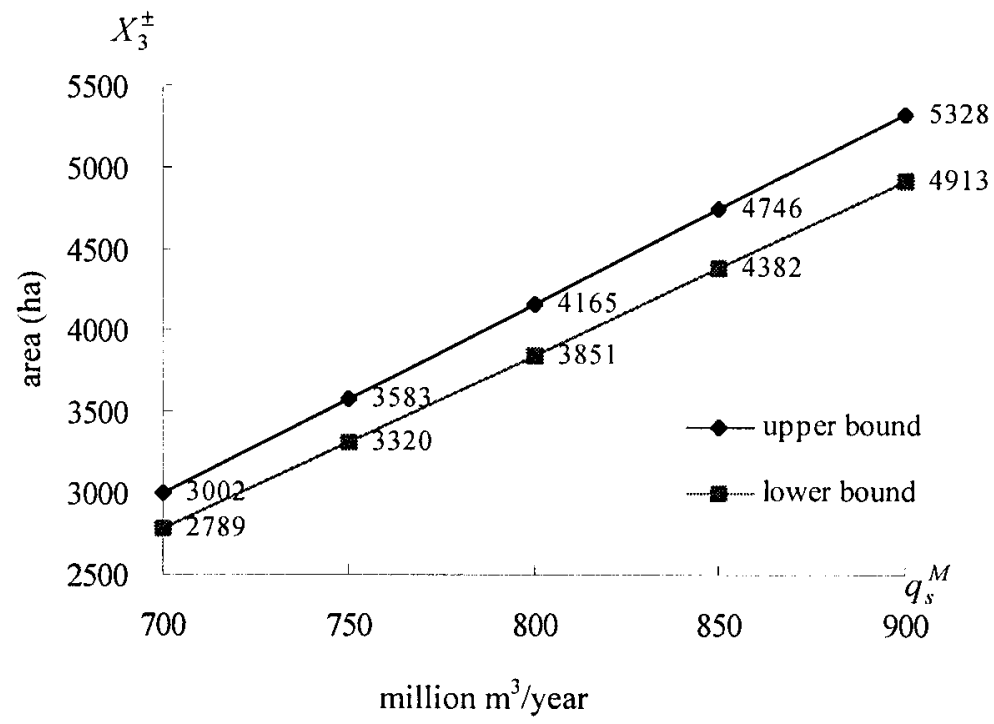

FIGURE 4 The optimum land allocation for industries $X_{3}^{ \pm}$corresponding to surface water supply capacity $q_{s}^{M}$ where $q_{s}^{ \pm}=\left[q_{s}^{M}-10, q_{s}^{M}+10\right]$. 
need for repeating many sensitivity analyses with respect to each system parameter. However, if the range to be examined for a system parameter is wider than the corresponding grey interval, traditional sensitivity analysis is still needed. The outcome will be "grey sensitivity analysis" because for each value of a system parameter, the result will be a range instead of a certain number for a system performance or decision variable value. Figure 3 and Figure 4 demonstrate the variation of the system performance $Z_{\mathrm{opt}}^{ \pm}$and the area for industries $X_{3}^{ \pm}$with respect to surface water supply capacity $q_{s}^{ \pm}$. The solutions were obtained by solving Model 2 and using the system parameters listed in Table I and II, except that $q_{s}^{ \pm}=\left[q_{s}^{M}-10, q_{s}^{M}+10\right]$. In Figure $2, Z_{\text {opt }}^{ \pm}$can be any value in the interval regions bounded by the upper bound curve and lower bound curve; similar interpretation is applicable for $X_{3}^{ \pm}$ in Figure 4.

\section{CONCLUSION}

An optimization problem for balancing land carrying capacity and groundwater consumption in Central Taiwan has been solved by using a problem-oriented grey linear programming (POGLP) algorithm. Traditional GLP algorithms were modified to make them suitable for general optimization problems. Further modifications were made to improve the applicability of resulting solutions, which lead to solving a problem-oriented GLP model. Satisfactory grey solutions were gained by the use of such a methodology. This can provide useful information to decision makers regarding the possible ranges of the policy decision-making, as the system parameters vary within their respective grey intervals.

The results indicate that all transferable lands currently used for crop and fish cultivation can be transferred to other usages such as industries, commerce, recreation, residence, and conservation. The increase in land use for recreation is ranked first. Groundwater will no longer be used for fish cultivation, thereby eliminating the major problem of land subsidence in the study area. To achieve this goal, the regulatory requirement of water resources fees should be imposed.

Sensitivity analyses were performed to demonstrate the variation relative to some decision variable values. It demonstrates interval regions instead of trend curves, which can be treated as two-dimensional or even multi-dimensional sensitivity analyses. Uncertainties in the examined system parameter ( $x$-axis), as well as the optimum system performance and decision variable values ( $y$-axis) are presented as grey intervals.

The GLP models presented in this paper should be regarded as a screening tool, which can identify good or non-inferior alternatives for the system. If a final single set of solutions is desired, additional analyses are then required. Nonlinear relationships between the system's elements may need to be taken into account and therefore, the optimization problem could turn out to be a nonlinear programming problem. Simulation techniques can also be applied to improving the application potential in each case study. Communications and negotiations between shareholders are probably needed before making a final decision.

\section{References}

[1] Sneh, M. (1996). Innovations in irrigation and water management. International Water and Irrigation Review, 16(1), 15-16.

[2] Bevers, M., Hof, J. and Troendle, C. (1996). Spatially optimizing forest management schedules to meet stormflow constraints. Water Resources Bulletin, 32(5), 1007-1015.

[3] Chang, N.-B., Wen, C. G. and Wu, S. L. (1995). Optimal management of environmental and land resources in a reservoir watershed by multiobjective programming. Journal of Environmental Management, 44, 145-161. 
[4] Sato, K. and Hoang, N. V. (1995). Recent Countermeasures for Land Subsidence and Groundwater Resources in Japan, Vol. 234. IAHS Publications, pp. 471-479.

[5] Cleveland, T. G. and Chuang, L-C. (1992). In Optimal aquifer management for controlling land subsidence. Proceedings of the National Conference on Water Resources Planning and Management, Baltimore, USA, August 2-6, ASCE, New York, NY, USA, pp. 872-877.

[6] Baek, T. K., Chishaki, T. and Tatsumi, H. (1994). Discriminant models and optimizing methodology for assignment of land use zone. Memoirs of the Faculty of Engineering, Vol. 45(2). Kyushu University, pp. $67-94$.

[7] Huang, G. H., Baetz, B. W. and Patry, G. G. (1992). A grey linear programming approach for municipal solid waste management planning under uncertainty. Civil Engineering Systems, 9, 319-335.

[8] Deng, J. (1985). Grey Systems (in Chinese). National Defense Industry Press, Beijing, China.

[9] Deng, J. (1986). Grey Prediction and Decision (in Chinese), Hua-Zhong Institute of Technology Press, Wu-Han, China.

[10] Huang, G. H. and Moore, R. D. (1993). Grey linear programming, its solving approach, and its application. International Journal of System Sciences, 24(1), 159-172.

[11] Huang, G. H., Baetz, B. W. and Patry, G. G. (1994). Grey dynamic programming for waste-management planning under uncertainty. Journal of Urban Planning and Development, 120(3), 132-156.

[12] Huang, G. H., Baetz, B. W. and Patry, G. G. (1994). Capacity planning for municipal solid waste management systems under uncertainty. Civil Engineering Systems, 11, 43-73.

[13] Huang, G. H., Baetz, B. W. and Patry, G. G. (1995). Grey quadratic programming and its application to municipal solid waste management planning under uncertainty. Engineering Optimization, 23, 201-223.

[14] Huang, G. H., Baetz, B. W. and Patry, G. G. (1993). A grey fuzzy linear programming approach for municipal solid waste management planning under uncertainty. Civil Engineering Systems, 10, 123-146.

[15] Chang, N.-B., Wen, C. G., Chen, Y. L. and Yong, Y. C. (1996). Optimal planning of the reservoir watershed by grey fuzzy multiobjective programming (I) theory. Water Research, 30(10), 2329-2334.

[16] Chang, N.-B., Wen, C. G., Chen, Y. L. and Yong, Y. C. (1996). Optimal planning of the reservoir watershed by grey fuzzy multiobjective programming (II) application. Water Research, 30(10), 2335-2340.

[17] Chang, N.-B. and Wang, S.F. (1995). A grey nonlinear programming approach for planning coastal wastewater treatment and ocean disposal system. Water Science and Technology, 32(2), 19-29.

[18] Chang, N.-B., Yeh, S. C. and Wu, G. C. (1999). Stability analysis of grey compromise programming and its applications. International Journal of System Science, 30(6), 571-589.

[19] Chang, N.-B. and Tseng, C. C. (1999). Optimal evaluation of expansion alternative for existing air quality monitoring network in an urban area by grey compromise programming. Journal of Environmental Management, 56(1), 61-77.

[20] Wu, C. C. and Chang, N.-B. The development of grey input-output analysis and its application for environmental cost allocation. European Journal of Operational Research, to be published in 2001.

[21] Yeh, S. C. (1996). Grey programming and its applications to water resources management, Ph.D. dissertation presented to the faculty of Graduate School of Cornell University, Ithaca, New York, USA.

\section{APPENDIX}

The basic definitions relating to grey programming as used in model formulation.

DEFINITION 1 A grey number $x^{ \pm}$is defined as an interval with known upper bound, $x^{+}$, and lower bound, $x^{-}$, but unknown distribution information.

$$
x^{ \pm}=\left[x^{-}, x^{+}\right]=\left\{t \in x^{ \pm} \mid x^{-} \leq t \leq x^{+}\right\}
$$

DEFINITION 2 Let $* \in\{+,-, \times, \div\}$ be an operation on grey numbers. For grey numbers $x^{ \pm}$ and $y^{ \pm}$, we have:

$$
x^{ \pm} * y^{ \pm}=[\min \{x * y\}, \max \{x * y\}], \quad x^{-} \leq x \leq x^{+}, \quad y^{-} \leq y \leq y^{+}
$$

DEFINITION 3 Let $\diamond \in\{=,<, \leq,>, \geq\}$. For $x^{ \pm}$and $y^{ \pm}$, their order relationship is as follows:

$$
x^{ \pm} \diamond y^{ \pm} \quad \text { iff } x^{-} \diamond y^{-} \text {and } x^{+} \diamond y^{+}
$$


DEFINITION 4 The whitened mid-value of $x^{ \pm}$is defined as $x^{M}$ :

$$
x^{M}=\frac{\left[x^{-}+x^{+}\right]}{2}
$$

DEFINITION 5 The degree of greyness of $x^{ \pm}$is defined as:

$$
\operatorname{deg}\left(x^{ \pm}\right)=\frac{\left[x^{+}-x^{-}\right]}{x^{M}}
$$

DEFINITION 6 Define Sign $\left(x^{ \pm}\right)$as follows:

$$
\begin{aligned}
\operatorname{Sign}\left(x^{ \pm}\right) & =1, \quad \text { if } x^{ \pm} \geq 0 \\
& =-1, \quad \text { if } x^{ \pm}<0 \\
& \text { not defined otherwise }
\end{aligned}
$$

DEFINITION 7 Grey Solutions or Stable Grey Intervals

Results obtained from a GP model can form a set of grey solutions or stable grey intervals if given that the system parameters and decision variable values are within their respective grey intervals, the system performance will also be within its grey interval.

Definition $8 \quad \mathbf{X}_{\mathbf{p}}, \mathbf{X}_{\mathbf{n}}$, and $\mathbf{X}_{\mathbf{z}}$

$\mathbf{X}_{\mathbf{p}}$ : the set of decision variables with a positive coefficient in the objective function.

$\mathbf{X}_{\mathbf{n}}$ : the set of decision variables with a negative coefficient in the objective function.

$\mathbf{X}_{\mathbf{z}}$ : the set of decision variables with a zero coefficient in the objective function. 